\title{
Experimental Liver Iron Measurement with the SQUID Gradiometer System
}

\author{
M. ŠKRÁTEK*, I. ŠIMÁČEK AND J. MAŇKA \\ Institute of Measurement Science, Slovak Academy of Sciences, Dúbravská cesta 9, 84104 Bratislava, Slovakia \\ An experimental system for noninvasive measurement of the iron stores in the liver of living human organism \\ has been designed and realized. This system enables to test the presence and to determine the iron concentration \\ in this organ. The principle of operation is based on measurement of small response (magnetic moment) of the \\ paramagnetic protein ferritin to the applied magnetic field on the complex diamagnetic background of other \\ body organs. The experiment was performed by modified SQUID system with the 2nd order gradiometer. At \\ present, the sensitivity of the system is $1 \mathrm{mg}$ Fe per gram of the wet liver, which from the point of view of clin- \\ ical diagnostics, enables to indicate the state of the liver iron overload, e.g., in hemochromatosis and hemosiderosis.
}

PACS numbers: 85.25.Dq, 75.50.Bp, 75.30.Cr

\section{Introduction}

Iron is an essential part of many vital processes in the human body. In principle, iron is found in hemoglobin in the blood, or mainly in the form of ferritin (FRT) in the liver. In practice, the iron content is determined in the body indirectly by measuring the serum FRT concentration, but clinical studies have shown that serum measurements are a poor predictor of iron stores [1]. The most accurate method is a needle biopsy, but it is significant risk and invasive operation. One alternative option may be a non-invasive measurement of the response of the liver to applied homogeneous magnetic field $[2-4]$. With respect to the presence of FRT, the liver appears as a paramagnetic object (mass susceptibility of FRT is $\approx 1600 \times 10^{-9} \mathrm{~m}^{3} \mathrm{~kg}^{-1}$ ), in contrast to surrounding tissues which actually exhibit diamagnetic properties with the mass susceptibility close to pure water $\left(\approx-9 \times 10^{-9} \mathrm{~m}^{3} \mathrm{~kg}^{-1}\right)$. The amount of FRT corresponds to the liver susceptibility, which has been shown to be a linear function of the liver iron concentration $\left(c_{\mathrm{Fe}}\right)$ [5]. Due to very low levels of $c_{\mathrm{Fe}}$, the measured values of magnetic induction $B_{\mathrm{m}}$ are $10^{-12} \mathrm{~T}$ or less. Therefore for reliable non-invasive liver iron stores determination only SQUID systems or magnetic resonance imaging (MRI) can be used [5-8].

\section{Method and instruments}

Our measuring apparatus was based on the RF SQUID system with 2nd order gradiometer, Fig. 1. Two rectangular Helmholtz coils $(\approx 3 \mathrm{~m} \times 2.3 \mathrm{~m})$ generate the homogeneous AC magnetic field with the intensity of $240 \mathrm{~A} / \mathrm{m}$ (peak-to-peak) and frequency of $2.8 \mathrm{~Hz}$ in the vertical direction. This frequency enabled to suppress the most

\footnotetext{
* corresponding author; e-mail: martin.skratek@savba.sk
}

voltage and current offsets, drifts and $1 / f$ noise. The measured signal was processed by an electronic unit operating with closed-loop negative feedback, whose aim was to increase the dynamic range and to linearize the operating characteristics. A significant improvement was achieved by using the electronic compensation derived from the magnetization current and using the efficient band-pass filters. With these modifications the system can measure very low susceptibility (in magnetically unshielded environment) corresponding to $B_{\mathrm{m}}$ of the magnitude of $10^{-13} \mathrm{~T}$.

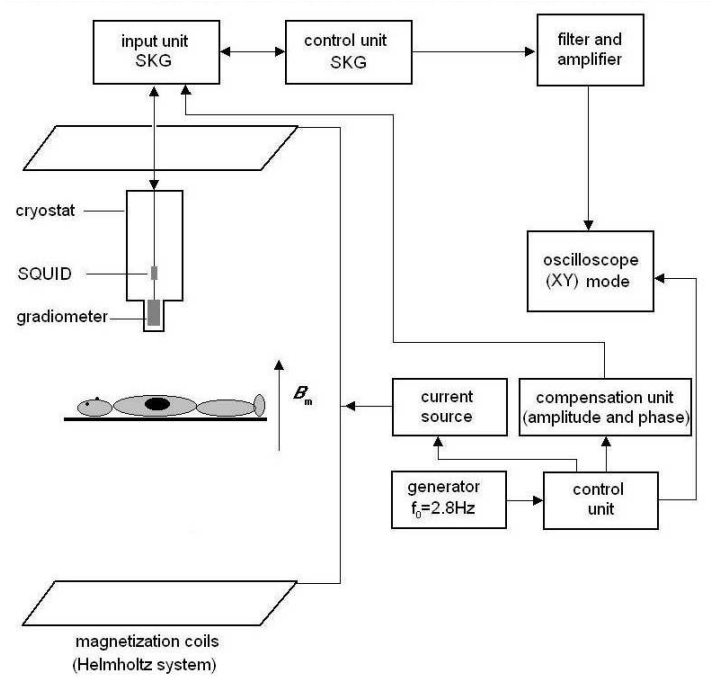

Fig. 1. Schematic of the experimental setup.

First, the dependence of $B_{\mathrm{m}}$ as a function of $c_{\mathrm{Fe}}$ has been measured on the torso model. An acrylic phantom of thorax and abdomen consisted of two containers filled with distilled water (diamagnetic background) containing two polyethylene cylindrical segments of the lungs model (air-filled) and the polyethylene cylindrical model 


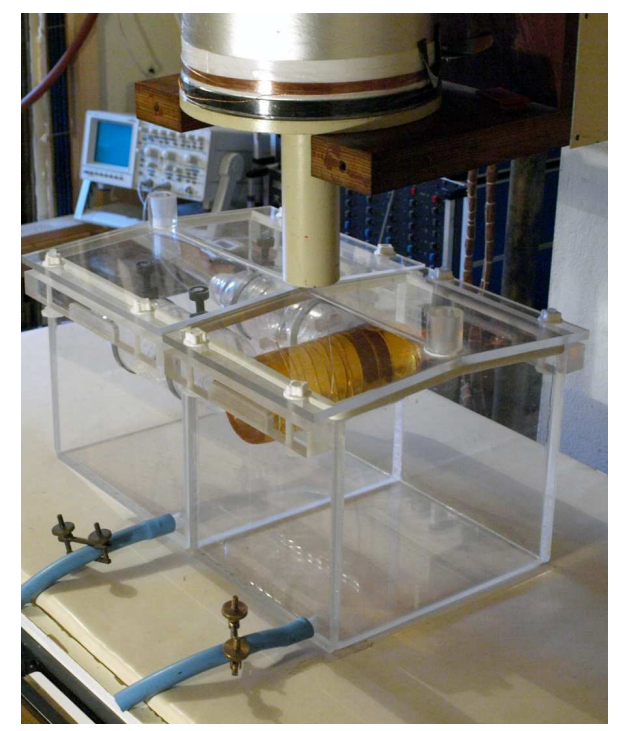

Fig. 2. Configuration of the model of thorax and abdomen consists of two containers filled with distilled water, models of lungs and liver. A part of the gradiometer sensor is shown above them.

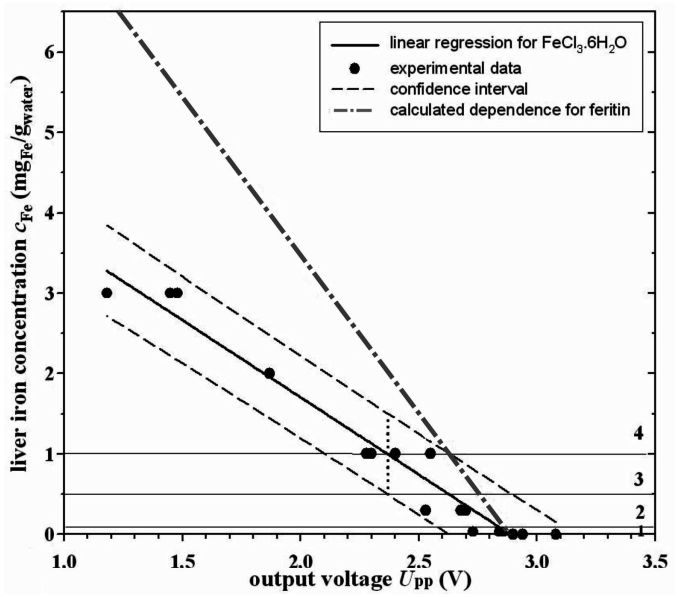

Fig. 3. Correlation between the liver iron concentration $\left(c_{\mathrm{Fe}}\right)$ and output voltage $U_{\mathrm{pp}}$ from the SQUID gradiometer system for the model measurement. Liver iron concentrations intervals: 1 - iron deficiency, 2 - normal iron storage, 3 - for some clinicians, only an increased iron level, 4 - iron overload.

of the liver with the volume of $1000 \mathrm{~cm}^{3}$ filled with various $c_{\mathrm{Fe}}$ of aqueous solution of $\mathrm{FeCl}_{3} \cdot 6 \mathrm{H}_{2} \mathrm{O}$, Fig. 2. This paramagnetic substance has been used with $c_{\mathrm{Fe}}$ in the range from $0.03 \mathrm{mg}_{\mathrm{Fe}} / \mathrm{g}_{\text {water }}$ to $3 \mathrm{mg} \mathrm{Fe} / \mathrm{g}_{\text {water }}$. A model of torso has been placed $2 \mathrm{~cm}$ below the cryostat bottom in such a way as to gradiometer axis passes the centre of the liver cylindrical model. Gradually in three series, the output voltages $U_{\mathrm{pp}} \sim B_{\mathrm{m}}$ for various $c_{\mathrm{Fe}}$ and for water (calibration medium) have been measured. Then the linear regression relation with the $95 \%$ confidence interval, Fig. 3, has been computed. As Fe is deposited in the liver

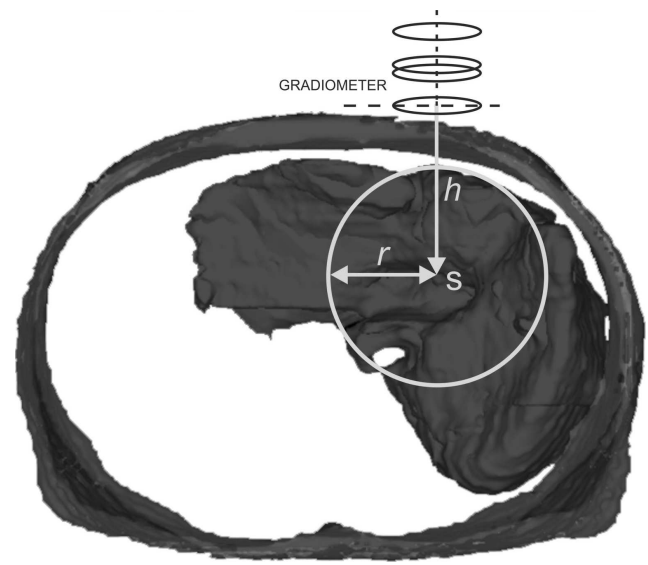

Fig. 4. MRI of the transversal section of the abdomen.

mainly in the form of FRT, the dependence between $c_{\mathrm{Fe}}$ and $U_{\mathrm{pp}}$ for $\mathrm{Fe}$ has been derived from the known values of susceptibilities of the $\mathrm{FeCl}_{3} \cdot 6 \mathrm{H}_{2} \mathrm{O}$ and FRT.

The measuring system has been experimentally verified with four patients. As the liver is large and nonsymmetrical organ, for the computation of $c_{\mathrm{Fe}}$ only its right largest part (lobus dexter) has been taken into account and approximated by the spherical volume $V$, Fig. 4 . As the value of $B_{\mathrm{m}}$ is influenced by the liver volume and its distance $h$ from the gradiometer, the mathematical model has been used, analogically as in [9], which introduces the corresponding relation $A_{\max }=f(V, h)$ for $V$ and $h$ in the range from 200 to $3000 \mathrm{~cm}^{3}$ and from 8 to $24 \mathrm{~cm}$, respectively. Measured value of $U_{\mathrm{pp}}$ was then corrected by factor $k$ which was determined as the ratio $A_{\max }$ (modeled liver) and $A_{\max }$ (measured liver). Location of the liver in the human body, its size and shape were obtained by MRI, Fig. 4 . The resulting value of $c_{\mathrm{Fe}}$ was determined directly from the relation between $k U_{\mathrm{pp}}$ and the ferritin-line, Fig. 3.

Considering the confidence interval dispersion and some clinical aspects, our SQUID system limit sensitivity for $c_{\mathrm{Fe}}$ has been determined to be $1 \mathrm{mg} F$ per gram of the wet liver.

\section{Conclusions}

The analysis has shown that it is difficult to correctly define the virtual midpoint position of the liver over which the sensor should be located. Similar problems occurred in ensuring the stable distance between the sensor and the surface of the human body, as it was affected by breathing. Despite these complications, the latter measurements have shown that this system could be used in the diagnosis and evolution of therapy for diseases with the iron overload, e.g., hemochromatosis and hemosiderosis. The resulting values of $c_{\mathrm{Fe}}$ obtained by SQUID system correlated, Table, with the values of $c_{\mathrm{Fe}}$ obtained by MRI measurements performed on these four patients in the Radiodiagnostic Clinic, Academician Ladislav Derer Hospital, Bratislava. 
TABLE

Results of $c_{\mathrm{Fe}}$ measurements by SQUID system and MRI. $V$ is the spherical volume of the liver, $h$ is the distance between the closest pickup coil and the centre of the liver, $k$ is the correction factor.

\begin{tabular}{c|c|c|c|c|c|c}
\hline \hline Patient & $\begin{array}{c}h \\
{[\mathrm{~cm}]}\end{array}$ & $\begin{array}{c}V \\
{\left[\mathrm{~cm}^{3}\right]}\end{array}$ & $k$ & $\begin{array}{c}k U_{\mathrm{pp}} \\
{[\mathrm{V}]}\end{array}$ & $\begin{array}{c}c_{\mathrm{Fe}} \\
{\left[\mathrm{mg}_{\mathrm{Fe}} / \mathrm{g}_{\text {liv }}\right]}\end{array}$ & $\begin{array}{c}c_{\mathrm{Fe}} \\
{\left[\mathrm{mg}_{\mathrm{Fe}} / \mathrm{g}_{\text {liv }}\right]}\end{array}$ \\
\hline 1 & 13 & 800 & 0.66 & 1.98 & $\mathbf{3 . 6 0}$ & $\mathbf{3 . 2 5}$ \\
2 & 17 & 1200 & 1.21 & 2.33 & $\mathbf{2 . 2 0}$ & $\mathbf{1 . 1 6}$ \\
3 & 11 & 440 & 0.75 & 2.78 & $\mathbf{0 . 4 5}$ & $\mathbf{0 . 3 2}$ \\
4 & 11 & 380 & 0.90 & 2.88 & $\mathbf{0 . 2 0}$ & $\mathbf{0 . 2 4}$
\end{tabular}

\section{Acknowledgments}

This work was supported by the Slovak Grant Agency for Science, project $2 / 0160 / 10$, by Agency of the Ministry of Education of the Slovak Republic for the Structural Funds of the EU, Operational Programme Research and Development, Project Code 262401200 19 and by Slovak Research and Development Support Agency, contract No. APVV-51-059005. The authors are also grateful to Dr. V. Belan and Dipl. Ing. M. Srbecký for MRI examinations of the patients.

\section{References}

[1] E. Angelucci, D. Baronciani, G. Lucarelli, M. Baldassarri, M. Galimberti, C. Giardini, F. Martinelli, P. Polchi, V. Polizzi, M. Ripalti, P. Muretto, Br. J. Haematology 89, 757 (1995).

[2] J. Bauman, J.V. Harris, J. Lab. Clin. Med. 20, 246 (1967).

[3] D.N. Paulson, R.L. Fagaly, R.M. Toussaint, R. Fischer, IEEE Trans. Magn. 27, 3429 (1991).

[4] C.M. Batuscheck, S.J. Williamson, J. Appl. Phys. 58, 3896 (1985).

[5] A.A.O. Carneiro, O. Baffa, in: Proc. 12th Int. Conf. on Biomagnetism, Eds. J. Nenonen, R.J. Ilmoniemi, T. Katila, Helsinki University of Technology, Helsinki 2001, p. 1011

[6] S.D. Penna, C.D. Gratta, S.D. Luizio, V. Pizzella, K. Torquati, G.L. Romani, Phys. Med. Biol. 44, N21 (1999).

[7] A.A.O. Carneiro, O. Baffa, J.P. Fernandes, M.A. Zago, Physiol. Meas. 23, 683 (2002).

[8] A.A.O. Carneiro, J.P. Fernandes, D.B. Araujo, J. Elias, A.L.C. Martinelli, D.T. Covas, M.A. Zago, I.L. Angulo, T.E.G. Piere, O. Baffa, Magn. Res. Med. 54, 122 (2005).

[9] F. Boháková, I. Šimáček, P. Jurdák, Sensors Actuators A 129, 150 (2006). 